\title{
STOMACH
}

\section{Relative contribution of mucosal injury and Helicobacter pylori in the development of gastroduodenal lesions in patients taking non-steroidal anti-inflammatory drugs}

\author{
C J Hawkey, J Næsdal, I Wilson, G Långström, A J Swannell, R A Peacock, N D Yeomans
}

Gut 2002;51:336-343

See end of article for authors' affiliations

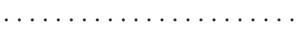

Correspondence to: C J Hawkey, Division of Gastroenterology,

University Hospital Queen's Medical Centre, Nottingham NG7 2UH, UK; cj.hawkey@nottingham.ac.uk

Accepted for publication 26 November 2001

\begin{abstract}
Background and aims: A past history of peptic ulceration increases the risk of an ulcer developing during non-steroidal anti-inflammatory drug (NSAID) use. Whether this is due to Helicobacter pylori infection or to reactivation of the original lesion is unclear.

Methods: We used multivariate regression analyses of three large similar trials to identify factors that placed patients at high risk of ulcer development or relapse. We compared the efficacy of omeprazole $20 \mathrm{mg}$ daily, misoprostol $200 \mathrm{\mu g}$ twice daily, and ranitidine $150 \mathrm{mg}$ twice daily in preventing ulcers and erosions at different sites and in patients who were $\mathrm{H}$ pylori positive and negative.

Results: Patients with endoscopic lesions (which healed) initially were significantly more likely than those without to develop further erosions or ulcers during treatment (rate ratio 2.12, 1.07-4.17). Risk mounted further with ulcers versus erosions, particularly those that had been slow to heal. There was a highly significant tendency for the relapse lesion to replicate the site and type of the original lesion (mean odds ratios ranging from 3 to 14). Treatment failure was significantly less likely with omeprazole than with placebo, misoprostol, or ranitidine. This advantage was especially evident in $H$ pylori positive patients receiving acid suppression $(5.7 \%$ v $16.6 \%$ for gastric ulcer with omeprazole).

Conclusions: Relapse of lesions in patients taking NSAIDs was highly site and type specific and not adversely affected by $\mathrm{H}$ pylori status. This strongly implies that local mucosal factors predispose to ulcer development in patients taking NSAIDs. Identification of the responsible mucosal changes would aid understanding and could promote better treatment.
\end{abstract}

$\mathrm{P}$ atients taking non-steroidal anti-inflammatory drugs (NSAIDs) have a substantially increased risk of ulcers and their complications. ${ }^{1-11}$ Modifying factors, which place some patients at particularly high risk, are now well recognised. They comprise drug related risk factors (the individual NSAID, its dose, coadministration of corticosteroids and warfarin) and the patient risk factors of old age and past history of ulcer. $^{679^{12-16}}$ Several issues concerning the influence of past history on NSAID associated ulcers are unresolved, including the mechanism by which this is mediated, the role of Helicobacter pylori, and the extent to which relapse is site specific.

We completed a programme of clinical trials involving over 2000 patients using NSAIDs. ${ }^{17-21}$ In these trials we studied patients with and without endoscopic lesions at baseline and variously investigated the efficacy of omeprazole $20 \mathrm{mg}$ daily, ranitidine $150 \mathrm{mg}$ twice daily and misoprostol $200 \mu \mathrm{g}$ twice daily as well as $H$ pylori eradication in the prevention of endoscopic lesions or symptoms. We used this large database to investigate what factors placed patients with individual gastroduodenal problems at increased risk of relapse.

\section{METHODS \\ Source of data \\ Trials}

Data were gathered from three large multicentre trials. These were the OPPULENT (Omeprazole versus Placebo as Prophylaxis against Ulcers or Erosions from NSAID Treatment) study and the maintenance phases of the OMNIUM (Omeprazole versus Misoprostol for NSAID Induced Ulcer Management) and ASTRONAUT (Acid Suppression Trial: Ranitidine or Omeprazole for NSAID Associated Ulcer Treatment) studies described in the accompanying paper [see page 336]. ${ }^{22}$ The efficacy of omeprazole as maintenance treatment after healing was compared with misoprostol and placebo in the OMNIUM study $^{18}$ and with ranitidine in the ASTRONAUT study. ${ }^{19}$ In the OPPULENT study, the ability of omeprazole to prevent ulcers, multiple erosions, or moderate to severe dyspepsia in patients found not to have clinically significant lesions at baseline endoscopy was compared with placebo. ${ }^{20}$ Because data from these studies suggested that the influence of $H$ pylori was different for gastric (GUs) and duodenal (DUs) ulcers, data from a fourth study, the HELP NSAIDs ${ }^{21}$ study which investigated $H$ pylori eradication, were used to explore whether $H$ pylori eradication might have a differential effect on gastric or duodenal ulceration.

\section{Conduct of the trials}

Patients achieving treatment success in the healing phase of the OMNIUM study were re-randomised to receive omeprazole $20 \mathrm{mg}$ once daily, misoprostol $200 \mu \mathrm{g}$ twice daily, or placebo as maintenance treatment while continuing to take their NSAIDs. ${ }^{18}$ Patients achieving treatment success in the healing phase of the ASTRONAUT study were likewise randomised to maintenance treatment with omeprazole $20 \mathrm{mg}$ or ranitidine $150 \mathrm{mg}$ twice daily while continuing NSAIDs. ${ }^{19}$ In some centres participating in the OMNIUM study, patients found not to have clinically significant lesions were entered directly into a prophylaxis trial, the OPPULENT study, in which they were randomised to receive omeprazole $20 \mathrm{mg}$ once daily or placebo in the OPPULENT study, also while continuing to take their NSAIDs.

Abbreviations: NSAIDs, non-steroidal anti-inflammatory drugs; RR, rate ratio; OR, odds ratio; $G U$, gastric ulcer; DU, duodenal ulcer; DDD, defined daily dose. 
In the HELP NSAIDs study, patients who were infected with $H$ pylori, who needed to take NSAIDs chronically, and who had an endoscopically documented NSAID associated ulcer at trial entry or in the previous five years, or current moderate or severe dyspepsia, were enrolled. ${ }^{21}$ They were randomised to receive $H$ pylori eradication treatment or control treatment. Omeprazole $20 \mathrm{mg}$, clarithromycin $500 \mathrm{mg}$, and amoxycillin $1000 \mathrm{mg}$ (each given twice daily for seven days) were used as $H$ pylori eradication treatment while controls received omeprazole with placebo antibiotics. After this, all patients received omeprazole $20 \mathrm{mg}$ daily for a further three weeks (and if unhealed an additional four weeks with omeprazole $40 \mathrm{mg}$ daily) with endoscopy at week 4 and if necessary at week 8 . All patients without significant lesions then entered a maintenance phase during which they continued NSAIDs but received no protective maintenance treatment and were followed up for six months.

\section{Comparability of the trials}

In order to allow the meta-analytical approach to pooled data reported in this paper, patients were entered into the OMNIUM, ASTRONAUT, and OPPULENT trials by a process of active recruitment, and patient characteristics allowing trial entry were similar for all of the studies. ${ }^{18-20}$ At trial entry, demographic and endoscopic data were collected systematically and identically for all three studies. Likewise, evaluation in all three studies was carried out to the same schedule, with clinical and endoscopic evaluation done routinely at one, three, and six months, or when clinical circumstances dictated. The same criteria we used for entry to the maintenance phase of the ASTRONAUT and OMNIUM studies (no ulcer, $<5$ erosions in the stomach or duodenum, and no more than mild dyspepsia) were used ${ }^{1}$ to define treatment success.

\section{End points}

Treatment failure was the primary end point of the OPPULENT study and of the maintenance phases of the OMNIUM and ASTRONAUT studies. It was a composite of endoscopic appearances and symptom control. Treatment failure occurred if a patient developed a GU or DU, had $>10$ erosions in the stomach or duodenum, had more than mild dyspepsia, or developed an adverse event. This combined end point was chosen to reflect the range of effects that NSAIDs have on patients who use them and to avoid the analytical distortion that arises when patients drop out of studies due to drug induced consequences for which there is no preplanned analysis. Consequently, our studies enabled us to show differential effects of trial drugs on ulcers, erosions, and symptoms in our studies. We also investigated relapse at one month, when the analysis of individual types of relapse was not confounded by prior dropout for other reasons. The HELP NSAIDs study was designed specifically to investigate the effect of $H$ pylori eradication on ulcer development and dyspepsia: erosions were not part of the end point of this study. In view of this difference from the other three studies, data from the HELP NSAIDs study were analysed separately and not used in any of the analyses (see next section) integrated across different trials.

\section{Analyses and patient cohorts}

The largest cohort of patients (cohort 1) consisted of all patients with significant lesions at baseline who had been managed in the maintenance phase of the OMNIUM and ASTRONAUT studies following successful treatment of these lesions in the healing phase.

Some centres participated in both the OMNIUM and OPPULENT studies. As all patients endoscopically screened at these dual participating centres could enter one or other of these trials, they represented the most homogeneous group, not distorted by trial selection, that we could study, and were designated cohort 2 .
Data from those patients in cohort 2 who only received placebo maintenance treatment were used to determine what factors, including the characteristics of the initial lesion, were associated with relapse development of ulceration or dyspepsia in the absence of active drug therapy. Cohort 1 was used to investigate risk factors for relapse following initial healing (as described in the accompanying paper ${ }^{22}$ ) and the interaction between these risk factors and the drug treatments used (placebo, omeprazole, misoprostol, ranitidine). This was done by analysing time until overall treatment failure over six months as well as relapse within one month. Data concerning relapse of individual lesions over six months are subject to confounding as removal of a patient because of relapse with one type of lesion potentially interferes with the statistical evidence of relapse with other types of lesion. These limitations do not apply to relapse at one month as few patients were removed from the study prior to this. One month relapse data were therefore used both to identify determinants of early relapse and to allow analysis of factors leading to a particular type of relapse (GU, DU, or erosions).

Primary analyses suggested that relapse was strongly influenced by the site and type of the initial lesion, with a possibly greater contribution of $H$ pylori infection to DU than GU relapse. Patients randomised to undergo $H$ pylori eradication or control treatment in the HELP NSAIDs study were therefore used to investigate the hypothesis that $H$ pylori eradication would differentially benefit those with initial DU compared with those with initial GU.

\section{Statistical approach}

Risk factors for relapse were identified by multivariate analysis. For the continuous variable, time until treatment failure, a Cox regression model was used and rate ratios (RR) for possible risk factors are presented. ${ }^{23}$ For the binary variables, relapse within one month (overall or due to specific reasons), a logistic regression model was used and odds ratios (OR) are presented. ${ }^{24}$ The factors entered into the models were selected prospectively and comprised: smoking status, past history of dyspepsia, past history of peptic ulcer, sex, H pylori status, age, individual NSAID, total number of defined daily doses (DDDs), corticosteroid use, type of arthritis, baseline lesion site and type, trial treatment in the healing phase, whether healing had occurred at four or eight weeks, and trial treatment in the maintenance phase. The $\chi^{2}$ test was used to quantify the strength of the association between the site and nature of the lesion found at initial screening endoscopy and the lesion found at relapse.

\section{RESULTS}

\section{Demography}

Cohort 1 consisted of the 1150 analysable patients entering the maintenance phase of the OMNIUM $(n=725)$ and ASTRONAUT $(n=425)$ studies (table 1). Of these, $728(63 \%)$ had originally had ulcers and $422(37 \%)$ had erosions. Among those with ulcers, 441 (61\%) originally had GUs only and 247 (34\%) originally had DUs only; GUs and DUs coexisted in 40 patients (5\%). Cohort 2 consisted of 296 analysable patients, of whom 150 were enrolled into the OPPULENT study and 146 into the maintenance phase of the OMNIUM study at the 18 centres which participated in both studies. The distribution of ulcers and erosions in patients who entered the OMNIUM study at these dual partition centres was similar to the distribution seen in cohort 1 as a whole (fig 1 in accompanying paper $^{22}$ ). Cohort 2-placebo consisted of all 105 patients in cohort 2 who received placebo prophylaxis/maintenance treatment. Of the 279 eligible patients who were analysed in the HELP NSAIDS study, 35 had active GUs only at baseline (13\%) and 40 DUs (14\%); GUs and DUs coexisted in six (2\%) patients. Table 1 shows the demographic features of all of 
Table 1 Demographics and patient characteristics

\begin{tabular}{|c|c|c|c|c|c|}
\hline Characteristic & $\begin{array}{l}\text { Cohort } 2 \\
(n=296)\end{array}$ & $\begin{array}{l}\text { Cohort } 1 \\
(n=1150)\end{array}$ & $\begin{array}{l}\text { Cohort } 1 \\
H \text { pylori-ve } \\
\left(n=571^{*}\right)\end{array}$ & $\begin{array}{l}\text { Cohort } 1 \\
\text { H pylori + ve } \\
\left(n=472^{*}\right)\end{array}$ & $\begin{array}{l}\text { HELP } \\
(n=279)\end{array}$ \\
\hline Age (y) (mean (SD)) & 57 (13) & $57(12)$ & 57 (13) & 57 (11) & 55 (11) \\
\hline Female & $176(59 \%)$ & $751(65 \%)$ & $71 \%$ & $61 \%$ & 195 (70\%) \\
\hline Smokers & $74(25 \%)$ & $261(23 \%)$ & $20 \%$ & $25 \%$ & $67(24 \%)$ \\
\hline Previous peptic ulcer & $87(29 \%)$ & $328(29 \%)$ & $78 \%$ & $82 \%$ & $116(42 \%)$ \\
\hline Previous dyspepsia & $256(86 \%)$ & 909 (79\%) & $25 \%$ & $34 \%$ & $138(49 \%)$ \\
\hline \multicolumn{6}{|l|}{ H pylori status } \\
\hline Unknown & $34(11 \%)$ & $107(9 \%)$ & & & - \\
\hline Negative & $173(58 \%)$ & $571(50 \%)$ & $100 \%$ & & - \\
\hline Positive & $89(30 \%)$ & $472(41 \%)$ & & $100 \%$ & $279(100 \%) \dagger$ \\
\hline \multicolumn{6}{|l|}{ Type of arthritis } \\
\hline RA & $128(43 \%)$ & $466(41 \%)$ & $43 \%$ & $41 \%$ & $116(42 \%)$ \\
\hline $\mathrm{OA}$ & $122(41 \%)$ & $471(41 \%)$ & $40 \%$ & $39 \%$ & - \\
\hline Other & 38 (13\%) & 175 (15\%) & $14 \%$ & $16 \%$ & $163(58 \%) \ddagger$ \\
\hline Combination & $8(3 \%)$ & $38(3 \%)$ & $3 \%$ & $3 \%$ & - \\
\hline \multicolumn{6}{|c|}{ Type of healed lesion } \\
\hline None & $150(51 \%)$ & - & - & - & - \\
\hline GU & $62(21 \%)$ & $441(38 \%)$ & $38 \%$ & $38 \%$ & $35(13 \%)$ \\
\hline GU+DU & $6(2 \%)$ & $40(3 \%)$ & $2 \%$ & $5 \%$ & $6(2 \%)$ \\
\hline DU & $32(11 \%)$ & $247(21 \%)$ & $17 \%$ & $27 \%$ & $40(14 \%)$ \\
\hline Erosions only (>11) & $46(15 \%)$ & 422 (37\%) & $42 \%$ & $29 \%$ & NR \\
\hline \multicolumn{6}{|l|}{ NSAIDs (DDD) } \\
\hline Unspecified* & 44 & 119 & $12 \%$ & $9 \%$ & \\
\hline $0-1$ & $96(32 \%)$ & $456(39.7 \%)$ & $34 \%$ & $47 \%$ & $59(21 \%)$ \\
\hline$>1$ & $156(53 \%)$ & $575(50 \%)$ & $54 \%$ & $44 \%$ & $220(79 \%)$ \\
\hline Steroids & $47(16 \%)$ & $178(15 \%)$ & & & $38(14 \%)$ \\
\hline \multicolumn{6}{|c|}{$\begin{array}{l}\text { *Helicobacter pylori status unknown in } 107 \text { patients. } \\
\text { †Inclusion criterion. } \\
\text { †Non-rheumatoid classified as other in this study. } \\
\text { OA, osteoarthritis; RA, rheumatoid arthritis; GU, gastric ulcer; DU, duodenal ulcer; NSAIDs, non-steroidal } \\
\text { anti-inflammatory drugs; DDD, defined daily dose. }\end{array}$} \\
\hline
\end{tabular}

these patients. NSAID use varied according to the trial, reflecting differences in the countries participating in the four studies.

\section{Treatment failure rates on placebo}

Among patients in cohort 2 who received placebo maintenance treatment, treatment failure was twice as likely in those who had required initial healing for a significant endoscopic lesion in the OMNIUM study $(69 \%)$ compared with those whose lower levels of injury had allowed direct randomisation to the OPPULENT study (36\%; RR 2.12; 95\% CI 1.07-4.17) (fig 1A). A similar pattern was seen in patients receiving active treatment with omeprazole but at a significantly lower level. In patients receiving placebo maintenance treatment, treatment failure was significantly more likely in men than women (56\% v 38\%; fig 1A), in smokers compared with non-smokers ( $55 \% \vee 42 \%$; fig 1A), and in those with osteoarthritis versus rheumatoid arthritis. In this group, $H$ pylori status did not affect relapse rates ( $H$ pylori positive $46 \% v$ negative $43 \%$ over six months; fig lA). In those with ulcers or multiple erosions requiring initial healing, $67 \%$ of $H$ pylori positive and $69 \%$ of $H$ pylori negative patients relapsed over six months.
A

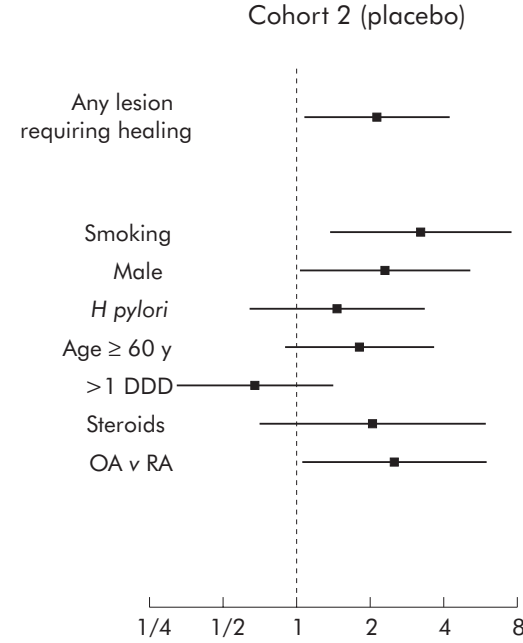

B

Cohort 1

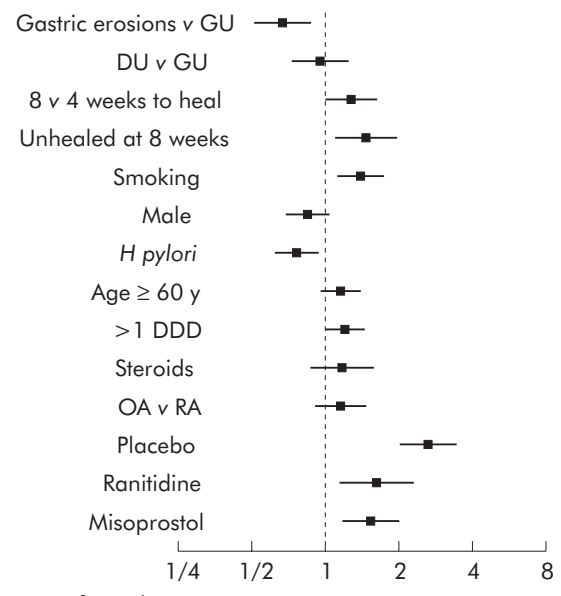

Rate ratio for relapse

Figure 1 Influences on risk of relapse over six months. (A) Influences on patients in cohort 2 who were assigned placebo maintenance treatment. (B) Data from those in cohort 1 who were taking a variety of maintenance treatments. Data are shown as rate ratios. RA, rheumatoid arthritis; OA, osteoarthritis; GU, gastric ulcer; DU, duodenal ulcer; DDD, defined daily dose. 
Table 2 Site and type specific relapse

\begin{tabular}{|c|c|c|c|c|c|c|c|c|c|c|}
\hline \multirow[b]{2}{*}{ Initial lesion } & \multirow[b]{2}{*}{$\mathrm{n}$} & \multicolumn{3}{|c|}{ Relapse over 6 months } & \multicolumn{6}{|c|}{$\%$ Site and type of lesion at relapse } \\
\hline & & Total & $\begin{array}{l}\text { With symptoms } \\
\text { or } A E\end{array}$ & With lesion & Body ulcer & $\begin{array}{l}\text { Antral } \\
\text { ulcer }\end{array}$ & $\begin{array}{l}\text { Duodenal } \\
\text { ulcer }\end{array}$ & $\begin{array}{l}\text { Body } \\
\text { erosions }\end{array}$ & $\begin{array}{l}\text { Antral } \\
\text { erosions }\end{array}$ & $\begin{array}{l}\text { Duodena } \\
\text { erosions }\end{array}$ \\
\hline Body ulcer & 80 & $38(47.5 \%)$ & $17(21.3 \%)$ & $23(28.8 \%)$ & 34.7 & 39.1 & 4.3 & 0 & 13.0 & 8.7 \\
\hline Antral ulcer & 349 & $165(47.3 \%)$ & $50(14.3 \%)$ & $120(34.4 \%)$ & 6.7 & 64.2 & 5.0 & 1.7 & 20.8 & 1.7 \\
\hline Duodenal ulcer & 247 & 101 (40.9\%) & $38(15.4 \%)$ & $88(27.5 \%)$ & 2.3 & 25.0 & 50.0 & 4.5 & 9.1 & 9.1 \\
\hline Body erosions & 33 & $8(24.2 \%)$ & $3(9.1 \%)$ & $5(15.2 \%)$ & 0 & 40 & 0 & 20 & 40 & 0 \\
\hline Antral erosions & 233 & $91(29.1 \%)$ & $43(18.5 \%)$ & $56(24.0 \%)$ & 7.1 & 23.2 & 3.6 & 3.6 & 58.9 & 3.6 \\
\hline Duodenal erosions & 56 & $25(44.6 \%)$ & $8(14.2 \%)$ & $17(30.4 \%)$ & 0 & 5.9 & 23.5 & 0 & 17.6 & 52.9 \\
\hline
\end{tabular}

Columns 6-11 show the type and site of lesion at relapse as a per cent of those with any lesion at relapse. Some patients relapsed for more than one reason.

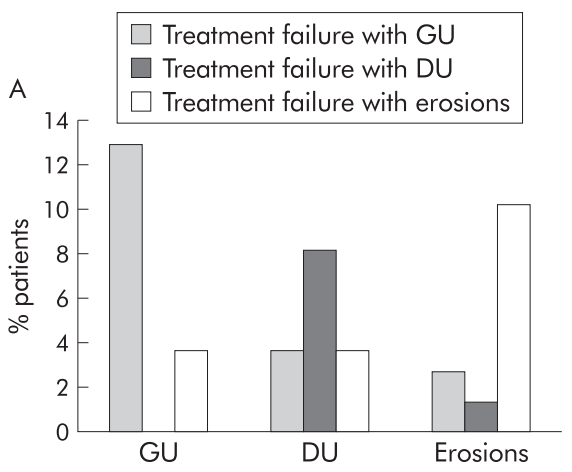

B

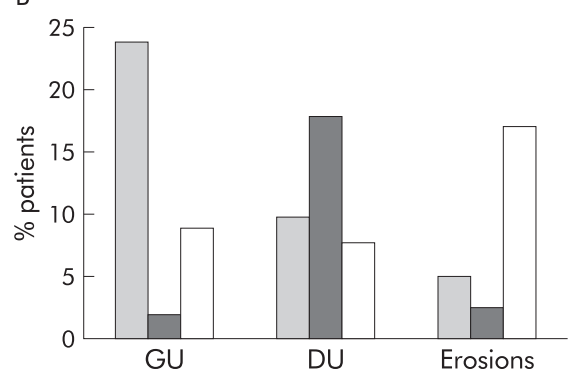

Figure 2 Site of relapse according to initial lesion. (A) One month data; (B) six month data. Data are grouped according to original lesion. GU, gastric ulcer; DU, duodenal ulcer.
Treatment failure following healing of significant lesions In cohort 1 , which included all patients who had suffered significant endoscopic lesions requiring initial healing therapy, treatment failure was significantly more likely in those with ulcers (48\%) than erosions (36\%) (fig 1B). Furthermore, lesions that were more difficult to heal were also significantly more likely to relapse (fig 1B). Treatment failure rates rose from $39 \%$ for those whose lesions had healed at four weeks to $49 \%$ for those who had required eight weeks of healing treatment and 50\% for those who had required further open treatment beyond eight weeks (fig 1B). Treatment failure was again significantly more likely in smokers (49\% v 40\%; fig 1B) while $H$ pylori infection was associated with a significantly reduced chance of treatment failure (36\% $v 47 \%$; fig $1 \mathrm{~B}$ and see below). There were trends to higher treatment failure in those

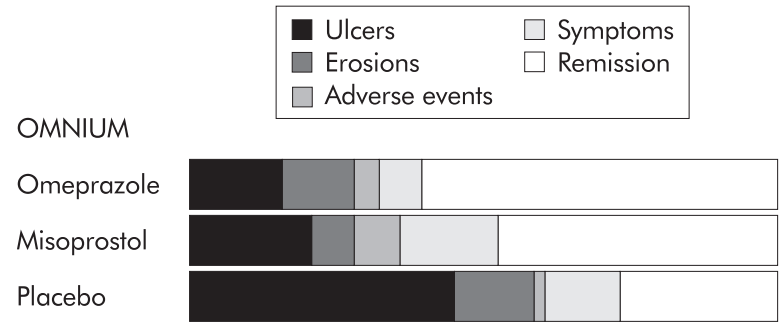

ASTRONAUT

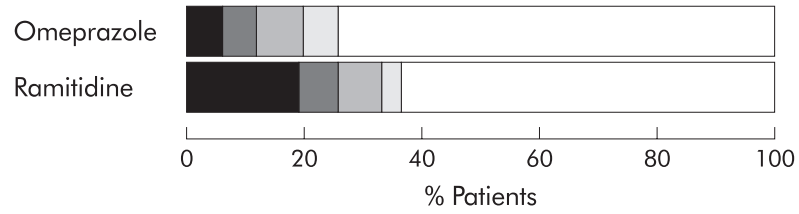

Figure 3 Mode of relapse. The proportion of patients remaining in remission and the reasons for treatment failure in those who experienced it over six months are shown for the OMNIUM and ASTRONAUT studies separately. taking $>1$ DDD of NSAID but these failed to reach statistical significance (fig 1B).

\section{Site and type specific nature of relapse}

There was a strong tendency for relapse to replicate the site and type of the original initial lesion (fig 2) and this was the dominant influence determining the lesion found in patients experiencing treatment failure. Among patients receiving placebo maintenance treatment, the OR for recurrence of the same site or type of lesion over six months was 6.2 (95\% CI 3.2-11.8) for GU, 13.6 (95\% CI 5.4-34.2) for DU, and 3.4 (95\% CI 1.7-6.1) for erosions. For patients in cohort 1, across all treatments, values were 4.5 (95\% CI 3.1-6.5) for GUs, 10.7 (95\% CI 6.1-19.0) for DUs, and 3.2 (95\% CI 2.2-4.8) for erosions. When the site within the stomach (antrum $v$ body/cardia) was further subdivided, this influence persisted and was seen to be particularly strong for relapse with the same type and site of lesion, although this was also seen for different types of lesions (erosions $v$ ulcers) at the same site as the initial lesion (table 2).

\section{Effect of drugs}

Treatment failure was significantly more likely if patients were taking placebo $(68 \%)$, misoprostol $(49 \%)$, or ranitidine $(38 \%)$ compared with omeprazole (32\%) (fig 1). Differences between ranitidine and misoprostol were not significant and may in part have reflected a lower overall treatment failure rate in the ASTRONAUT compared with the OMNIUM study. As shown in fig 3, the pattern of relapse varied according to drug treatment. Overall, the rate of ulcer development was lower on omeprazole compared with placebo, misoprostol, or ranitidine while there were fewer erosions with misoprostol.

\section{Interaction between drugs and $\boldsymbol{H}$ pylori}

Treatment failure (table 3)

The beneficial effects of $H$ pylori were associated with a lower treatment failure rate in those receiving acid suppressive drugs. Thus only $22 \%$ of patients receiving omeprazole $20 \mathrm{mg}$ 
Table 3 Relationship between Helicobacter pylori and reason for treatment failure

\begin{tabular}{|c|c|c|c|c|c|c|}
\hline \multirow[b]{3}{*}{ Trial } & \multicolumn{6}{|c|}{ Reason for treatment failure } \\
\hline & \multicolumn{2}{|l|}{ All causes } & \multicolumn{2}{|l|}{ GU } & \multicolumn{2}{|l|}{ DU } \\
\hline & H pylori- & H pylori+ & H pylori- & H pylori+ & H pylori- & H pylori+ \\
\hline \multicolumn{7}{|l|}{ OMNIUM } \\
\hline Placebo & $69.0 \%$ & $66.7 \%$ & $33.3 \%$ & $25.9 \%$ & $4.6 \%$ & $18.5 \%$ \\
\hline Misoprostol & $45.6 \%$ & $53.2 \%$ & $8.2 \%$ & $9.2 \%$ & $8.2 \%$ & $11.0 \%$ \\
\hline Omeprazole & $43.4 \%$ & $24.8 \%$ & $16.6 \%$ & $5.7 \%$ & $2.8 \%$ & $0 \%$ \\
\hline \multicolumn{7}{|l|}{ ASTRONAUT } \\
\hline Omeprazole & $37.6 \%$ & $19.2 \%$ & $10.6 \%$ & $1.9 \%$ & $1.2 \%$ & $0 \%$ \\
\hline Ranitidine & $43.8 \%$ & $31.0 \%$ & $14.6 \%$ & $17.0 \%$ & $2.1 \%$ & $4.0 \%$ \\
\hline
\end{tabular}

daily experienced treatment failure if they were $H$ pylori positive compared with $41 \%$ of those who were $H$ pylori negative. Corresponding percentages for ranitidine were $31 \%$ and $44 \%$, respectively. Conversely, treatment failure tended to be higher with misoprostol in $H$ pylori positive versus negative patients (53\% v 46\%). $H$ pylori had no influence on the overall likelihood of treatment failure in patients taking placebo $(67 \%$ v 69\%).

\section{Development of specific lesions}

Data on individual lesions at relapse over six months are presented descriptively. Formal statistical analysis of these relationships was not performed because the risks of confounding made it invalid to do so.

\section{Gastric ulcer}

Overall, fewer GUs developed in patients infected with $H$ pylori compared with $H$ pylori negative individuals. This was seen principally in patients receiving acid suppression (table 3 ). Omeprazole was consistently more effective in preventing GUs in those who were $H$ pylori positive than those who were $H$ pylori negative (table 3 ). By contrast, the proportion of patients developing a GU on misoprostol was similar for $H$ pylori negative and $H$ pylori positive patients (table 3 ). Somewhat more placebo recipients developed a GU if they were $H$ pylori negative $(33.3 \%)$ than positive $(25.9 \%)$.

\section{Duodenal ulcer}

A converse pattern was seen for DU (table 3), with DUs developing in $18.5 \%$ of patients on placebo who were $H$ pylori positive compared with $4.6 \%$ in those who were $H$ pylori negative. Very few patients developed DUs on acid suppression (13/699, $1.9 \%$ overall) whether they were $H$ pylori positive or negative (table 3). Among patients receiving misoprostol, 8.2\% developed DUs if $H$ pylori negative and $11.0 \%$ if $H$ pylori positive. Of patients experiencing site specific relapse of DUs, $58 \%$ were $H$ pylori positive compared with only $36 \%$ for site specific relapse of GU.

\section{Erosions}

Erosions developed in $\mathbf{1 5 . 5 \%}$ of patients on placebo who were $H$ pylori positive and in $11.1 \%$ of those who were $H$ pylori negative.

\section{Early relapse}

\section{Overall treatment failure}

Overall, 251 patients experienced relapse within one month (22\%), of whom 85 had GUs, 32 had DUs, and 68 had multiple erosions. The rest relapsed with symptoms. Overall, there was a significantly higher likelihood of treatment failure in patients whose initial lesions had taken more than eight weeks to heal (fig 4), in those who received higher NSAID doses, in smokers, in women, and in patients with osteoarthritis ( $v$ rheumatoid arthritis). Early treatment failure was less likely with H pylori infection. Overall, early treatment failure was more likely in patients receiving ranitidine, misoprostol, or placebo compared with omeprazole $20 \mathrm{mg}$ (fig 4).

\section{Individual lesions}

Overall treatment failure rates did not differ for different initial lesions but site and type of the initial lesion was the dominant determinant of the site and type of the lesion at relapse (fig 4). The overall OR for the same site or type of relapse over six months was 3.7 (95\% CI 1.8-8.0) for GU versus DU, 28.1 (95\% CI 6.1-129.9) for DU versus GU, and 3.6 (95\% CI 2.1-6.2) for erosions versus ulcers.

Gastric ulcer

Apart from having a GU initially, early relapse with GU was also more likely in smokers. There were trends towards enhanced relapse with higher NSAID doses and protection by $H$ pylori infection (fig 4).

\section{Duodenal ulcer}

Having an initial DU was the dominant and only significant influence on DU relapse (fig 4).

\section{Erosions}

Apart from having multiple erosions initially, there was only a trends towards an increasing risk of early relapse with gastric erosions due to higher NSAID doses.

\section{Site specific relapse following $\boldsymbol{H}$ pylori eradication}

Given that patients with $H$ pylori infection were rather more likely to develop DUs and less likely to develop GUs compared with $H$ pylori negative patients, we used data from the HELP NSAIDs study to investigate whether $H$ pylori eradication had a differential effect on relapse of GUs and DUs. Although numbers are small, these data again show that relapse was highly site specific, but that there was no obvious difference in GU recurrence with $H$ pylori eradication compared with non-eradication. Following eradication, there were no recurrent DUs compared with six of 25 in the group that did not receive eradication therapy (fig 5).

\section{DISCUSSION}

Because NSAID ulcers are usually silent, patient management has to be determined on the basis of risk assessment. ${ }^{25}$ Our studies provide information that is of major practical value in achieving accurate risk assessment. They have shown that simply having a significant lesion at endoscopy doubles the risk of a further lesion during both active and placebo maintenance treatment, and that risk mounts with ulcers versus erosions and with the time the ulcer takes to heal. Our studies thus confirm earlier evidence, with a wider group of patients, that relapse is site preferential and strongly support local mucosal pathology ${ }^{26-31}$ as the major determinant of subsequent outcome in patients using NSAIDs. Furthermore, recent data 
Treatment failure

Original lesions

Erosions $v$ ulcers

DU $v$ GU

8 weeks to heal

$>8$ weeks to heal

Smoking

Male

H pylori

Age 60+y

$>1$ DDD

Steroids

$O A \vee R A$

Plac v omep

Ran $v$ omep

Miso $v$ omep

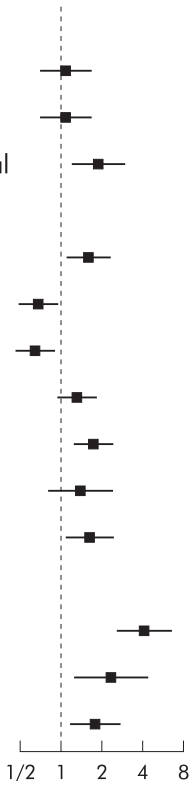

GU

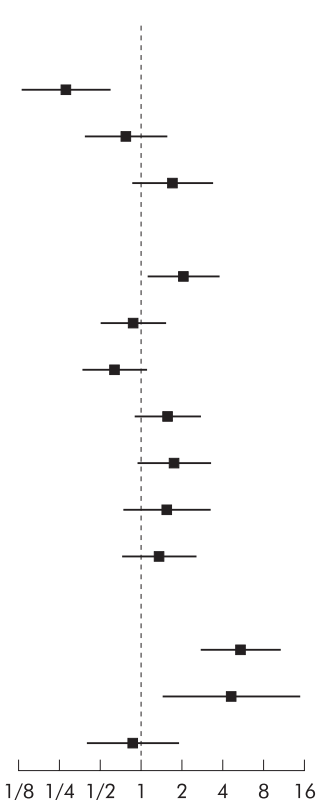

DU

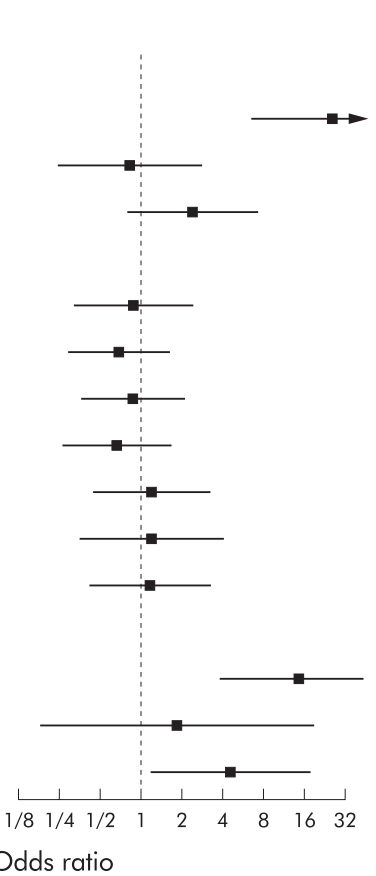

Erosions

Original lesions

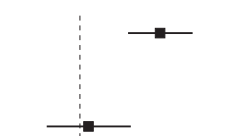

Erosions $v$ ulcers

DU v GU

8 weeks to heal

$>8$ weeks to heal

Smoking

Male

H pylori

Age $60+y$

$>1$ DDD

Steroids

OA $v$ RA

Plac $v$ omep

Ran $v$ omep

Miso $v$ omep

Figure 4 Effect of potential risk factors on endoscopic findings at one month. Differences are expressed as odds ratios with $95 \%$ confidence intervals. Data concerning any clinically significant lesion versus none are from cohort 2 . Data concerning ulcer versus erosions and gastric ulcer (GU) versus duodenal ulcer (DU) are from cohort 1. DDD, defined daily dose; RA, rheumatoid arthritis; OA, osteoarthritis; Plac, placebo; Omep, omeprazole $20 \mathrm{mg}$ daily; Miso, misoprostol 200 jg twice daily; Ran, ranitidine $150 \mathrm{mg}$ twice daily.
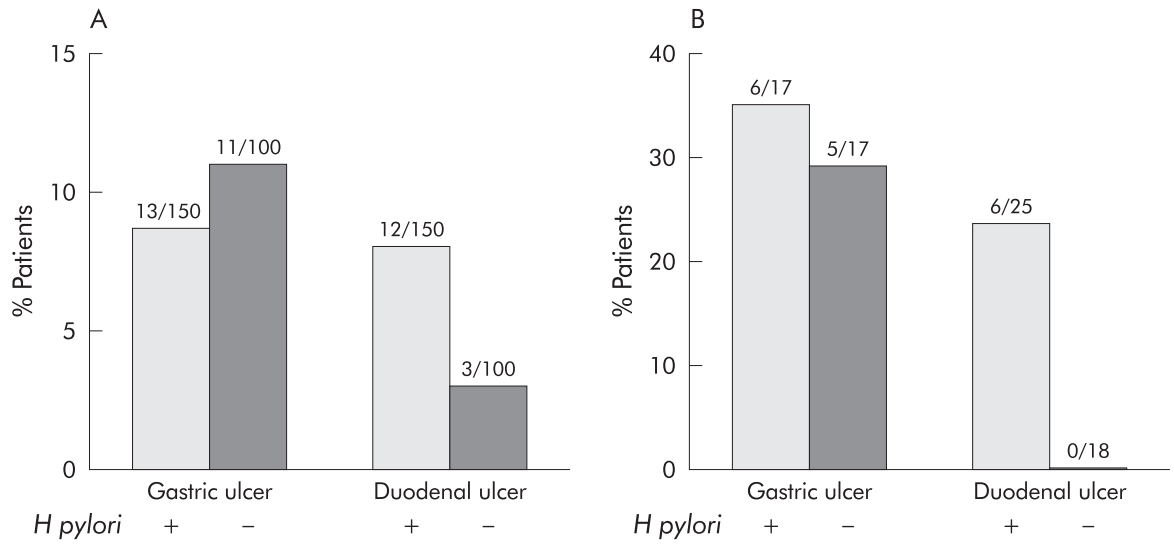

Figure 5 Site of relapse with and without eradication of Helicobacter pylori. Data from the HELP NSAIDs trial. Patients who were $H$ pylori positive were recruited. Half were given eradication treatment and half placebo. Data are shown by final $H$ pylori status. Intention to treat results are similar. (A) All patients. (B) Patients whose site of relapse replicated the site of the original lesion.

suggest that such an influence continues to predispose to further ulceration, albeit at a lower level, even when patients stop taking their NSAID or switch to a cyclooxygenase 2 inhibitor. ${ }^{32}$

There are two plausible explanations for this striking observation. Firstly, NSAIDs may reactivate ulceration at the site of a previously healed lesion, either because the ulcer scar is vulnerable to re-ulceration ${ }^{26-31}$ or because an underlying defect which led to the initial ulcer continues to render that area more vulnerable in the future. This would explain the site specific nature of relapse, which has previously been reported for "idiopathic" or $H$ pylori induced ulcers and variously ascribed to deficient vascularity, kinetic strain, or vulnerable scar tissue..$^{26-31}{ }^{33-35}$ Secondly, the underlying pathogenetic mechanisms of different NSAID associated lesions may vary. This could explain the type specific nature of relapse embodied in the observation that patients who have erosions initially tend to have erosions at relapse while those who have ulcers initially tend to have ulcers at relapse. Our observations concern endoscopic ulcers. In general, finding endoscopic evidence of erosions or ulcers is predictive of more serious later pathology, including clinical and complicated ulcers. Similarly, studies of mucosal protection with endoscopic end points have been broadly predictive of performance in clinical trials, including outcome studies. How far differences with respect to erosions versus ulcers are reflected in clinical outcome requires further study.

At first sight, the apparent differential effects of individual drugs on prevention of erosions (misoprostol more effective) or ulcers (omeprazole more effective) would seem to support a clinically significant two component model of NSAID damage that might underlie differences in the natural history in those with ulcers or erosions. ${ }^{36}$ However, while this may be 
true, an alternative explanation for the larger number of erosions at relapse with omeprazole is that they arise by confounding. If erosions are partially healed ulcers, their number may rise with a therapeutically active agent. We used a relatively low dose of misoprostol in our studies, recommended by the manufacturer as the preferred maintenance dose when they were started. It is likely that a higher dose would have been more effective, although at the expense of more adverse effects. Likewise, higher than normal doses of $\mathrm{H}_{2}$ antagonists have been reported to be more effective than normal doses. ${ }^{37}{ }^{38}$ In our patients, relapse (particularly in the month after healing) was also more likely with higher NSAID doses and in women (perhaps reflecting a higher weight adjusted dose in women in this study). The apparent increase in early relapse with osteoarthritis versus rheumatoid arthritis was inconsistent across individual lesions, does not seem biologically plausible, and may have occurred by chance.

Among the patients we studied, $H$ pylori infection did not increase risk and indeed was associated overall with a significant reduction in risk in actively treated patients. While the effect of $H$ pylori infection on NSAID ulceration is controversial, ${ }^{39} 40$ its effects (whether beneficial or harmful) have, in all studies, been small by comparison with the influence of the initial site and type of lesion that we report as the dominant influence here. The beneficial effects of $H$ pylori were seen in the prevention of GUs in patients receiving acid suppression. Such a beneficial effect was not seen for DUs or in patients receiving misoprostol. Indeed, in the HELP NSAIDs study there appeared to be a reduction in DU but not GU relapse following $H$ pylori eradication, although numbers were very small. A further prospective study specifically designed to investigate this hypothesis would be needed to determine if this is a true effect. Other observations we have made support the notion that the pathogenesis of NSAID associated DUs, GUs, and erosions may differ. Thus there was a dose dependent increase in treatment failure with GUs, erosions, and H pylori negative DUs, suggesting a primary pathogenic role for NSAID related changes, but not with $H$ pylori positive DUs where there was no dose dependence, suggesting that NSAIDs play a more permissive role.

In view of these data, there would now appear to be no empirical reason to pursue a strategy of $H$ pylori eradication for patients with established GUs associated with non-selective NSAID use on the grounds of efficacy. Our data clearly show that the target of treatment is site specific recrudescence of previous ulceration. It is not surprising that removal of a coexistent ulcer risk factor does not influence this markedly. Indeed, some consequences of $H$ pylori infection, such as increased prostaglandin synthesis and increased effectiveness of acid suppression, have the potential to influence outcome in a favourable direction. Nevertheless, many authors continue to advocate $H$ pylori eradication ${ }^{39}$ on the basis that it remains a continuing ulcer risk in patients who stop their NSAIDs and may predispose to gastric cancer in those who continue (despite extensive evidence that NSAID use is associated with a reduction in such risk). ${ }^{40}{ }^{41}$ In practical terms, $H$ pylori eradication is probably desirable in patients who are able to stop taking NSAIDs entirely but may be useless or harmful in those who have to continue, particularly if they have had GUs. Moreover, acid suppression is more effective in the healing and prevention of ulcers in patients who are $H$ pylori positive.

\section{Authors' affiliations}

C J Hawkey, Division of Gastroenterology, University Hospital, Queen's Medical Centre, Nottingham, UK

J Næsdal, I Wilson, G Långström, R A Peacock, AstraZeneca R\&D Mölndal, S-431 83 Mölndal, Sweden

A J Swannell, Department of Rheumatology, City Hospital, Hucknall Road, Nottingham, UK

N D Yeomans, Department of Medicine, University of Melbourne, Western Hospital, Footscray, Victoria 3011 , Australia
Conflict of interest: C J Hawkey has received research funding and/or honoraria from: AstraZeneca, Alizyme, Boehringer Ingelheim, Glaxo Wellcome, Merck, NicOx, Novartis, Parke Davis, Searle, SmithKline

Beecham, and Wyeth Lederle.

\section{REFERENCES}

1 Hawkey CJ. Non steroidal anti-inflammatory drugs and peptic ulcers. Facts and figures multiply, but do they add up? BM 1990;300:278-84.

2 Gabriel SE, Jaakkimainen L, Bombardier C. Risk for serious gastrointestinal complications related to use of nonsteroidal anti-inflammatory drugs: a meta-analysis. Ann Intern Med 1991;115:787-96.

3 Fries JF, Williams CA, Bloch DA, et al. Non-steroidal anti-inflammatory drug-associated gastropathy: incidence and risk factor models. Am J Med 1991:91:213-22.

4 Langman MJS, Weil J, Wainwright $P$, et al. Risk of bleeding peptic ulcer associated with individual non-steroidal anti-inflammatory drugs. Lancet 1994;343: 1075-8

5 Garcia Rodriguez LA, Jick $\mathrm{H}$. Risk of upper gastrointestinal bleeding and perforation associated with individual non-steroidal anti-inflammatory drugs Lancet 1994:343:769-72.

6 Smalley WE, Ray WA, Daugherty JR, et al. Nonsteroidal anti-inflammatory drugs and the incidence of hospitalizations for peptic ulcer disease in elderly persons. Am J Epidemiol 1995;141:539-45.

7 Henry D, Lim LL-Y, Rodriguez LAG, et al. Variability in risk of gastrointestinal complications with individual non-steroidal anti-inflammatory drugs: results of a collaborative meta-analysis. BM 1996;312:1563-6.

8 Wolfe MM, Lichtenstein DR, Singh G. Gastrointestinal toxicity of non-steroidal anti-inflammatory drugs. N Eng J Med 1999;340:1888_ 99 .

9 Hernandez-Diaz S, Rodriguez LA. Association between nonsteroidal anti-inflammatory drugs and upper gastrointestinal tract bleeding/perforation: an overview of epidemiologic studies published in the 1990s. Arch Intern Med 2000;160:2093-9.

10 Tramer MR, Moore RA, Reynolds DJM, et al. Quantitative estimation or rare adverse events which follow a biological progression. A new mode applied to chronic NSAID use. Pain 2000;85:169-82.

11 Weil J, Langman M, Wainwright $P$, et al. Peptic ulcer bleeding: accessory risk factors and interactions with non-steroidal anti-inflammatory drugs. Gut 2000;46:27-31

12 Piper JM, Ray WA, Daugherty JR, et al. Corticosteroid use and peptic ulcer disease: Role of nonsteroidal anti-inflammatory drugs. Ann Intern Med 1991;114:735-40.

13 Shorr RI, Ray WA, Daugherty JR, et al. Concurrent use of nonsteroidal anti-inflammatory drugs and oral anticoagulants places elderly persons at high risk for hemorrhagic peptic ulcer disease. Arch Intern Med 1993; 153: 1665-70.

14 Hallas J, Lauritsen J, Dalsgard Villadsen et al. Nonsteroidal anti-inflammatory drugs and upper gastrointestinal bleeding, identifying high-risk groups by excess risk estimates. Scand J Gastroenterol 1995; 30:438-44

15 Lanas Al, Remacha B, Esteva F, et al. Risk factors associated with refractory peptic ulcers. Gastroenterology 1995;109:1 124-33.

16 Singh G, Ramey DR, Morfeld D, et al. Gastrointestinal tract complications of nonsteroidal anti-inflammatory drug treatment in rheumatoid arthritis. A prospective observational cohort study. Arch Intern Med 1996;156:1530-6.

17 Ekstrom P, Carling L, Wetterhus S, et al. Prevention of peptic ulcer and dyspeptic symptoms with omeprazole in patients receiving continuous non-steroidal anti-inflammatory drug therapy. A Nordic multicentre study. Scand J Gastroenterol 1996;31:753-8.

18 Hawkey CJ, Karrasch JA, Szczepanski L, et al. Omeprazole compared with misoprostol for ulcers associated with nonsteroidal antiinflammatory drugs. N Engl J Med 1998;338:727-34.

19 Yeomans ND, Tulassay Z, Juhasz L, et al. A comparison of omeprazole and ranitidine for treating and preventing ulcers associated with non-steroidal anti-inflammatory drugs. New Eng J Med 1998;338:719-26.

20 Cullen D, Bardhan DK, Eisner M, et al. Primary gastroduodenal prophylaxis with omeprazole for non-steroidal anti-inflammatory drug users. Aliment Pharmacol Ther 1998;12:135-40.

21 Hawkey CJ, Tulassay Z, Szczepanski L, et al. Helicobacter pylori eradication in patients taking non-steroidal, anti-inflammatory drugs: The HELP NSAIDs Study. Lancet 1998;352:1016-21.

22 Hawkey CJ, Næsdal J, Wilson I, et al. Influence of sex and Helicobacter pylori on development and healing of gastroduodenal lesions in non-steroidal anti-inflammatory drug users. Gut 2002;51:344-50.

23 Cox DR, Oakes D. Analysis of survival data. London: Chapman and Hall, 1984 .

24 Hosmer DW Jr, Lemeshow S. Applied logistic regression. New York: John Wiley and Sons, 1984.

25 Peterson WL, Cryer B. COX-1-sparing NSAIDs is the enthusiasm justified? JAMA 1999;282:1961-3

26 Moshal MG, Sitaels JM, Khan F. Tripotassium dicitratobismuthate chewing tablets and cimetidine and DeNol. Scand J Gastroenterol 1979; 14(suppl 54):48-51. 
27 Pan S, Liao C-H, Lien G-S, et al. Histological maturity of healing duodenal ulcers and ulcer recurrence after treatment with colloida bismuth subcitrate or cimetidine. Gastroenterology 1991;101:1187-91.

28 Sakaki N, Takemoto T. The relationship between endoscopic findings of gastric ulcer scar and ulcer relapse. J Clin Gastroenterol 1993;17/suppl 1):S64-9.

29 Kimura K, Yoshida Y, Kihira K, et al. Endoscopic ultrasonographic (EUS) evaluation of the quality of gastric ulcer healing. Gastroenterol Jpn 1993;28(suppl 5):178-85.

30 Tarnawski A, Tanove K, Santos AM, et al. Cellular and molecular mechanisms of gastric ulcer healing. Is the quality of mucosal scar affected by treatment. Scand J Gastroenterol 1995;210(suppl):9-14.

31 Schmassmann A, Tarnawski A, Gerber HA, et al. Antacid provides better restoration of glandular structures within the gastric ulcer scar than omeprazole. Gut 1994;35:896-904.

32 Hawkey CJ, Laine L, Harper SE, et al. Influence of risk factors on endoscopic and clinical ulcers in patients taking rofecoxib or ibuprofen. Aliment Pharmacol Ther 2001;15:1593-601.

33 Cappell MS. Profound spatial clustering of simultaneous peptic ulcers. Gut 1989;30:1329-33.
34 Oi $M$, Ito $Y$, Kumagai $F$, et al. A possible dual control mechanism in the origin of peptic ulcer. A study on ulcer location as affected by mucosa and musculature. Gastroenterology 1969;57:280-93.

35 Piasecki C. Blood supply to the human gastroduodenal mucosa with special reference to the ulcer-bearing areas. J Anat 1974;118:295-35.

36 Whittle BJ. Temporal relationship between cyclooxygenase inhibition, as measured by prostacyclin biosynthesis, and the gastrointestinal damage induced by indomethacin in the rat. Gastroenterology 1981:80:94-8.

37 Taha AS, Hudson N, Hawkey CJ, et al. Famotidine for the prevention of gastric and duodenal ulcers caused by non-steroidal anti-inflammatory drugs. N Engl J Med 1996;334:1435-9.

38 Ten Wolde S, Dijkmans BA, Janssen $M$, et al. High-dose ranitidine for the prevention of recurrent peptic ulcer disease in rheumatoid arthritis patients taking NSAIDs. Aliment Pharmacol Ther 1996;10:347-51.

39 Calvet X, Larrosa M, Font J, et al. On dissonances, Helicobacter pylori and NSAIDs. Aliment Pharmacol Ther 2000;14:497-8.

40 Hawkey CJ. Reply-On dissonances, Helicobacter pylori and NSAIDs. Aliment Pharmacol Ther 2000;14:499-500.

41 Logan RF, Little J, Hawtin PG, et al. Effect of aspirin and non-steroida anti-inflammatory drugs on colorectal adenomas: case-control study of subjects participating in the Nottingham faecal occult blood screening programme. BM 1993;307:285-9.

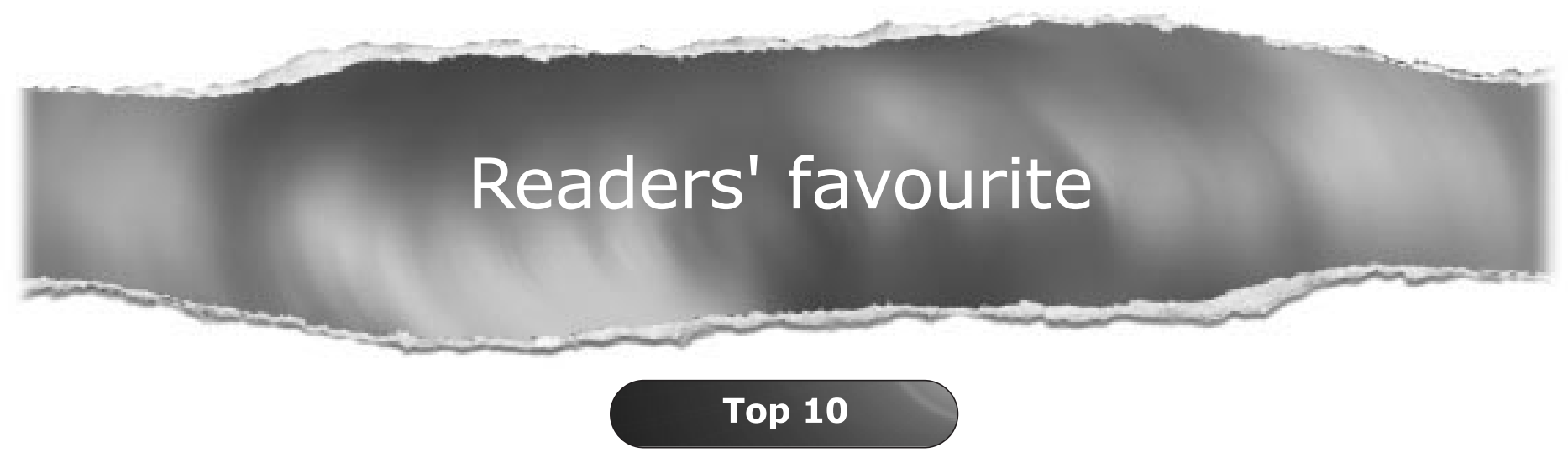

Click on the "Top 10" button on the homepage to see which are the best read articles each month

www.gutjnl.com 